\title{
Results of an internal audit on the survival of patients with uterine sarcoma
}

\author{
(D) Florian Ebner ${ }^{1}$, (D) Saskia Wiedenmann², (D) Inga Bekes², (D) Wolfgang Janni², (D) Nikolaus de Gregorio², \\ (1) Amelie de Gregorio2 \\ 1Frauenklinik, HELIOS Amper Klinikum, Dachau, Germany \\ 2Klinik für Frauenheilkunde und Geburtshilfe, Universität Ulm, Ulm, Germany
}

\section{Abstract}

Objective: In the last 5 years there has been much discussion about the surgical procedure for uterine fibroids, and essentially, also uterine sarcoma. Still there exists no reliable presurgical diagnostic tool to differentiate between benign fibroids and uterine sarcomas. The aim of this study was to confirm the suspected association between intraoperative spread of tumor by morcellation and impaired outcomes in patients with sarcoma.

Material and Methods: After the local ethics commission positively reviewed the study protocol, the oncologic database of our university hospital was retrospectively reviewed for patients with uterine sarcomas over a time period of 13 years (2002-2015). Data was extracted from the medical files and survival information was collected by contacting the patient's general practitioners if last follow-up-status was older than 6 months. For the analysis, patients were split into two groups with either intrasurgical morcellation $(\mathrm{M}+)$ or no morcellation (M-) regarding information provided by the surgical report.

Results: Data on 57 patients with uterine sarcoma were available for further analysis. The median age and body mass index of the patients was 63 years and $27 \mathrm{~kg} / \mathrm{m}^{2}$, respectively. The sarcoma subtypes were 25 leiomyosarcoma, 19 carcinosarcoma, 9 endometrioid stroma sarcoma, 3 adenosarcoma, and one case without further differentiation. In the majority, no morcellation was performed (M- group, $\mathrm{n}=44)$ and 51 patients received open surgery (3 laparoscopic, 1 vaginal, and 2 incomplete surgeries). The median time of follow-up was 31 months. The disease-free survival was 50.5 months and the Cox regression analysis showed a hazard ratio of 3.06 [no significant difference between the two subgroups $(p=0.079 ; 95 \%$ confidence interval (CI): 0.9-10.6)]. The overall survival was found as 62.2 months and the Cox regression analysis showed a hazard ratio of 3.216 with a statistically significant difference between the two subgroups ( $\mathrm{p}=0.013 ; 95 \%$ CI: $1.3-8.1)$.

Conclusion: Despite the efforts to find a pre-surgical diagnostic tool, the clinical situation remains unsatisfactory. Overall sarcoma prevalence is low during the last 13 years at our university center, but morcellation occurred in a relevant portion of patients (13 of 57). If sarcoma is suspected or diagnosed then en-bloc resection of the uterus can prolong survival. Thus, morcellation of the uterus and not the surgical technique (en-bloc resection) is the prognostic factor and should be avoided in any suspicious case. (J Turk Ger Gynecol Assoc 2019; 20: 15-22)

Keywords: Sarcoma, uterine, hysterectomy, fibroids, risk factors

Received: 7 June, 2018 Accepted: 8 October, 2018

\section{Introduction}

Uterine sarcomas are a rare malignant entity of the uterus $(1,2)$ and are diagnosed in approximately $0.2-0.5 \%$ (2-5) of all cases of hysterectomies. The World Health Organization (WHO) classification differentiates between mesenchymal and mixed (mesenchymal and epithelial) tumors (6). Pure mesenchymal tumors are further differentiated into leiomyosarcomas (LMS), endometrial stromal sarcomas, and smooth muscle tumors of uncertain malignant potential, and mixed tumors are differentiated into adenosarcomas and carcinosarcomas (CS). CS along with mullerian mixed tumors, malignant mesodermal mixed tumors, and metaplastic carcinoma are considered a subclass of endometrial carcinoma (6). Generally, the prognosis of uterine sarcomas is unfavorable. Whilst the International Federation of Gynecology and Obstetrics (FIGO) stage Ia still has a 5 -year survival rate of $84.3 \%$, this dramatically decreases for stage II (43.6\%), III (38.8\%), and IV (19.8\%) (7). 
Clinical symptoms of this heterogenic tumor group might include uterine enlargement, bleeding, and pelvic pain, and are therefore rather unspecific and also common in many other gynecologic diseases (e.g. uterine leiomyomas). Blood parameters (serum lactate dehydrogenase, carcinoembryonic antigen, CA125, CA19-9, and CA15-3 (3,8), or presurgical imaging [ultrasound (US), magnetic resonance imaging (MRI), computed tomography (CT)] has room for improvement $(3,9,10)$. Two case series for MRI scans found a positive predictive value of $52 \%$ (11) (negative predictive value 100\%) and a specificity of $92 \%$ (12) to presurgically identify uterine sarcoma. Even positron emission tomography-CT is not capable of differentiating between benign uterine leiomyomas and malignant uterine sarcomas (13). US elastography case reports on the differential diagnosis of fibroids and sarcoma are being published (14), reporting a 'typical' mosaic pattern in sarcomas compared with a homogenous pattern in fibroids.

Given the fact that myomas are a common finding in gynecologic patients, distinguishing between suspected malignant tumors and benign fibroids has great implications for clinical practice. Due to fertility aspects, hypermenorrhea, and urogynecologic symptoms, surgery in patients with fibroids is frequent. Surgical treatment of benign uterine leiomyoma is either focused on the removal of the myoma or the complete uterus. With increasing availability of laparoscopic equipment and surgical training, the number of open abdominal surgeries has decreased (15-17) over the last decades in favor of laparoscopic-assisted vaginal hysterectomy, total laparoscopic hysterectomy, or laparoscopic supracervical hysterectomy, which are offered to women who do not wish to bear children. A uterus-conserving approach is offered if family planning is not complete. The vaginal approach is limited by patient factors [e.g. body mass index (BMI), previous vaginal births/surgeries, size of uterus] and surgeons skills; however, the laparoscopic pathway is possible even with larger uterus size $(18,19)$, increased BMI (20), offers rapid recovery, less blood loss (21) and a low complication rate (22). Laparoscopic surgery can be considered the standard surgical treatment of uterine leiomyomas, with large specimens often requiring morcellation to be removed through trocar insertion sites. This will increase the numbers of uterine sarcomas accidentally through morcellation.

During morcellation, small visible and microscopic parts of the tissue may be dispersed within the abdomen. This might lead to peritoneal dissemination of tumor tissue (23). Based on the increased numbers of laparoscopic surgeries with subsequent morcellations, the rate of uterine sarcomas accidentally being morcellated will also increase. Given the general poor prognosis of uterine sarcomas $(3,7,24)$ and the lack of sufficiently reliable preoperative diagnostic procedures to identify uterine sarcomas, this article tries to answer if accidental morcellation of uterine sarcomas in abdominal, vaginal or laparoscopic surgery has a negative impact on patients in terms of increased recurrence rates and/or decreased survival.

\section{Material and Methods}

Our university cancer centre database has continuously collected data for all oncologic patients since 2002. This database was searched for patients with uterine sarcoma or CS including patients up to January 2016. Though the documentation input in the database is performed by welltrained and specialised personnel, the documenting of rare diseases might have been misclassified and not shown in the results. To maximise the results, the search was conducted by diagnosis or surgical procedure. The result list was then checked for agreement with the inclusion criteria. All patient files with a hysterectomy as surgical treatment at the certified gynaecologic oncology centre with age $>18$ years were included in this analysis. The available date were analysed retrospectively for tumour stage, histologic subtype, and route of surgery (open/laparoscopic or vaginal). The route of surgery was noted and patients were classified according to the surgical and pathology reports in uterine morcellation $(\mathrm{M}+)$ or en-bloc resection (M-). Morcellation in an intraabdominal bag was not performed. The disease-free survival (DFS) and overall survival (OS) were compared between these two groups. Living status and follow-up was provided by the routine annual cancer centre follow-up. If these data were not available, the patient's general practitioner was contacted. Ethics approval (308/2012) was given by the Local Ethic Committee of Ulm University.

Parameters for the statistical analysis using the SPSS software (IBM $^{\circledR}$ SPSS ${ }^{\circledR}$ Statistics Version) were age at histologic confirmation of sarcoma (WHO classification), BMI, American Society of Anesthesiologists status, date and status of follow-up, primary tumour stage [tumour, node, metastasis (TNM), FIGO classification 2009], resection status ( $\mathrm{R} 0$ or $\mathrm{R} 1 / 2$ ), receptor status (oestrogen, progesterone) and location of recurrence, as well as further treatments (e.g. radiotherapy, chemotherapy). Due to the small sample sizes, no analyses were performed based on the influence of morcellation regarding the different histologic subtypes.

Descriptive statistical analysis was used to determine average, median, standard deviation, minimum and maximum, likelihood, and percentiles. The OS/DFS were defined in months starting from the date of surgery to the last documented vital status/date of recurrence. Survival was analysed using KaplanMeier analysis, the log-rank test, and Cox regression. $\mathrm{P}<0.05$ was considered statistically significant. Further multivariate testing for differences was performed using the WilcoxonMann-Whitney test, univariate testing with the Fisher's exact test, and the Mann-Whitney U test. 


\section{Results}

The database search identified 59 patients with sarcoma treated at Ulm University Hospital, Department of Gynecology and Obstetrics between 2002 and 2015. Two patients were excluded because no follow-up data were available. The average age of the remaining 57 patients was 63 years and their average BMI was $27 \mathrm{~kg} / \mathrm{m}^{2}$. The histologic subtypes were
LMS ( $n=25)$, CS $(n=19)$, endometrial stroma sarcoma $(n=9)$, high-grade sarcoma $(n=3)$, and sarcoma without further classification $(n=1)$. Twenty-nine patients were not TNM classified and only clinically staged, 15 patients were pT1, 10 pT2, and 5 pT3 after surgery. Detailed information on the two subgroups is presented in Table 1 . Hormone receptors were negative or unknown in the majority of the specimens. Table 2

Table 1. Patient and tumour details in the subgroups

\begin{tabular}{|c|c|c|c|c|c|}
\hline & & & Group M- & Group M+ & Total \\
\hline \multirow{6}{*}{ Tumor size pT } & \multirow{2}{*}{ pT1 } & Number, $\mathrm{n}$ & 12 & 3 & 15 \\
\hline & & \% Within the subgroup & $52.2 \%$ & $60.0 \%$ & $53.6 \%$ \\
\hline & \multirow{2}{*}{ pT2 } & Number, $\mathrm{n}$ & 10 & 0 & 10 \\
\hline & & \% Within the subgroup & $43.5 \%$ & $0.0 \%$ & $35.7 \%$ \\
\hline & \multirow{2}{*}{ pT3 } & Number, n & 1 & 2 & 3 \\
\hline & & \% Within the subgroup & $4.3 \%$ & $40.0 \%$ & $10.7 \%$ \\
\hline \multirow{2}{*}{$\mathrm{p}=0.029$} & \multirow{2}{*}{ Total } & Number, n & 23 & 5 & 28 \\
\hline & & \% Within the subgroup & $100.0 \%$ & $100.0 \%$ & $100.0 \%$ \\
\hline \multirow{4}{*}{ Lymphnodes pN } & \multirow{2}{*}{ pN0 } & Number, $\mathrm{n}$ & 12 & 0 & 12 \\
\hline & & \% Within the subgroup & $80.0 \%$ & $0.0 \%$ & $75.0 \%$ \\
\hline & \multirow{2}{*}{ pN1 } & Number, $\mathrm{n}$ & 3 & 1 & 4 \\
\hline & & \% Within the subgroup & $20.0 \%$ & $100.0 \%$ & $25.0 \%$ \\
\hline \multirow{2}{*}{$\mathrm{p}=0.25$} & \multirow{2}{*}{ Total } & Number, $\mathrm{n}$ & 15 & 1 & 16 \\
\hline & & \% Within the subgroup & $100.0 \%$ & $100.0 \%$ & $100.0 \%$ \\
\hline \multirow{4}{*}{ Metastasis M } & \multirow{2}{*}{ M0 } & Number, $\mathrm{n}$ & 17 & 3 & 20 \\
\hline & & \% Within the subgroup & $89.5 \%$ & $37.5 \%$ & $74.1 \%$ \\
\hline & \multirow{2}{*}{ M1 } & Number, $\mathrm{n}$ & 2 & 5 & 7 \\
\hline & & \% Within the subgroup & $10.5 \%$ & $62.5 \%$ & $25.9 \%$ \\
\hline \multirow{2}{*}{$\mathrm{p}=0.011$} & \multirow{2}{*}{ Total } & Number, $\mathrm{n}$ & 19 & 8 & 27 \\
\hline & & \% Within the subgroup & $100.0 \%$ & $100.0 \%$ & $100.0 \%$ \\
\hline Age & & Median in years & 65 & 56 & 63 \\
\hline \multicolumn{6}{|l|}{$\mathrm{p}=0.045$} \\
\hline \multirow{10}{*}{ Histology } & \multirow{2}{*}{ LMS } & Number, $\mathrm{n}$ & 18 & 7 & 25 \\
\hline & & \% Within the subgroup & $40.9 \%$ & $53.8 \%$ & $43.9 \%$ \\
\hline & \multirow{2}{*}{ ESS } & Number, $\mathrm{n}$ & 6 & 3 & 9 \\
\hline & & \% Within the subgroup & $13.6 \%$ & $23.1 \%$ & $15.8 \%$ \\
\hline & \multirow{2}{*}{$\mathrm{CS}$} & Number, n & 17 & 2 & 19 \\
\hline & & \% Within the subgroup & $38.6 \%$ & $15.4 \%$ & $33.3 \%$ \\
\hline & \multirow{2}{*}{ AS } & Number, $\mathrm{n}$ & 2 & 1 & 3 \\
\hline & & \% Within the subgroup & $4.5 \%$ & $7.7 \%$ & $5.3 \%$ \\
\hline & \multirow{2}{*}{ Other } & Number, $\mathrm{n}$ & 1 & & 1 \\
\hline & & \% Within the subgroup & $2.3 \%$ & & $1.8 \%$ \\
\hline \multirow{2}{*}{$\mathrm{p}=0.548$} & \multirow{2}{*}{ Total } & Number, $\mathrm{n}$ & 44 & 13 & 57 \\
\hline & & \% Within the subgroup & $100 \%$ & $100 \%$ & $100 \%$ \\
\hline
\end{tabular}

TNM classification with subgroup morcellated (M+) and non-morcellated (M-); p values with exact Fisher test; TNM: (T) tumour size, (N) lymph nodes, (M) metastasis; LMS: Leiomyosarcoma; ESS: Endometrioid stroma sarcoma; CS: Carcinosarcomas; AS: Adenosarcoma; pT/pN: Pathologic classification of the tumour size or lymph node status 
provides further patient and histologic details. It is noteworthy that our $\mathrm{M}+$ subgroup had significantly larger tumours and patients with primary metastases.

The surgical access was abdominal in 51 patients, laparoscopic in 3 patients, and vaginal in one. Another two patients were considered incurable after the surgery had started. Three patients were started laparoscopically and converted to open abdominal surgery due to very large fibromas with adhesions $(n=2)$ and once to repair a bladder lesion. Twenty-eight patients were considered R0, 5 patients had a microscopic tumour, and 24 patients could not be classified. Further details regarding the surgery are provided in Table 3. Further treatments included radiotherapy $(n=11)$, chemotherapy $(n=25)$, and no further therapy $(n=10)$. Cause of death was known in 10 patients (sarcoma $n=2$, other causes $n=8$ ) with a further 15 patients deceased. The remaining 32 patients had a documented live status, who were used for further analysis. Disease recurrence was found in 20 patients. Recurrence occurred mostly as distant or a combination of distant and local metastases, followed by local and lymph node metastases. The uterus was removed without morcellation (M-) in 44 surgeries and 13 cases were considered morcellated $(\mathrm{M}+)$.

The DFS of all patients was 50.5 months and Cox regressions analysis showed a hazard ratio of 3.06 without any significant difference between the two subgroups [12.3 months $(\mathrm{M}+)$ vs 54.9 months (M-); $\mathrm{p}=0.079 ; 95 \%$ confidence interval $(\mathrm{CI})$ : 0.9-10.6]. The OS was found as 62.2 months. Thereby, Cox regression analysis showed a hazard ratio of 3216 and was statistically significantly different between the two subgroups [19.2 months $(\mathrm{M}+)$ vs 69.2 months $(\mathrm{M}-)$; $\mathrm{p}=0.013 ; 95 \%$ CI: 1.3 8.1]. DFS and OS are presented in Figure 1.

Table 2. Patient and sarcoma details

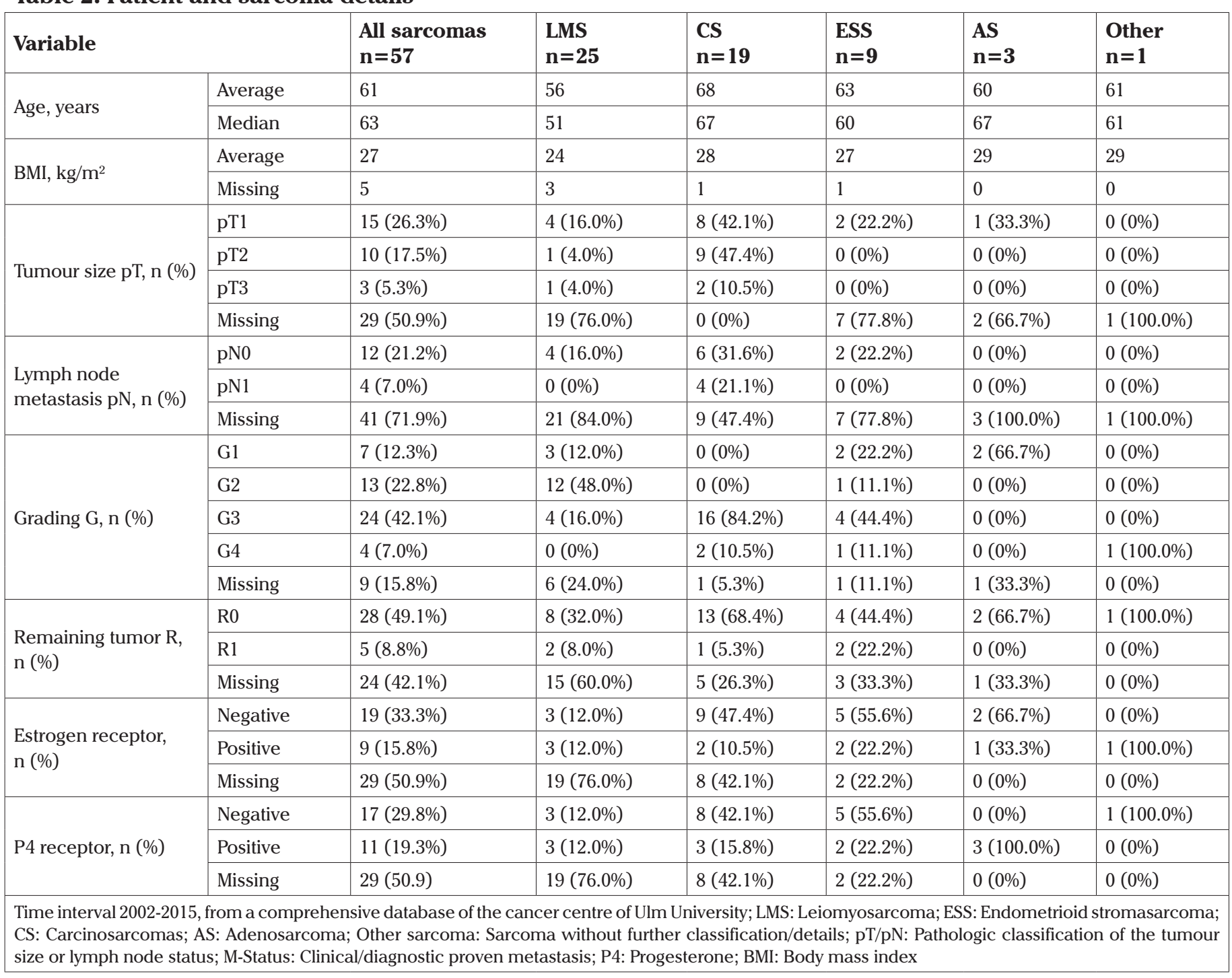




\section{Discussion}

Laparoscopic resection of uterine fibroids has been under scrutiny in recent years due to the lack of a preoperative diagnostic tool for uterine sarcoma. Reliable data on sarcoma incidence, diagnosis, prognosis, and further treatment are still rare. Prognosis for patients with uterine sarcoma is generally poor with a 5-year survival of 50\% (25-30) (M+ vs M-: median OS 10.8 vs 39.6 months or 5 -y OS $46 \%$ vs $73 \%)(26,31)$. Differences exist among subtypes and type of resection for survival. Endometrial stroma sarcoma and complete resection seem to be beneficial for the patient (32-34). Even in our small retrospective analysis, the results are in line with existing data on the recurrence pattern with mostly distant recurrence (35). Further data were published showing a decrease in survival if sarcomas were morcellated (31,36-39). The morcellation resulted in a tissue spill on various intraabdominal organs such as ovaries, liver, and omentum, and it did not matter which surgical technique (vaginal, laparoscopic or open) was used (40). Seidman et al. (41) published a reduced OS in patients with morcellation and LMS, but could not show this in other subtypes of uterine sarcoma. Similar results were published by other authors $(26,42,43)$. Our data contribute to these conflicting results; DFS is not significantly different between the two surgical study groups - though there is a statistical trend indicating a disadvantage for the morcellated group. However the M+ subgroup had significant larger tumours and patients with primary metastases. However, our analysis shows a significant difference for OS, contrary to data published by Morice et al. (38). In their analysis, 123 patients were closely followed up and no significant difference in the 6-month recurrence rate was found between the two treatment groups (M- vs $\mathrm{M}+$ ). However, the database includes various histologic subtypes (i.e. LMS, CS and endometrial stroma sarcoma with low and high-grade cases). The cases series by Liu et al. (44) indicates that there might be a very aggressive biologic subgroup, yet to be identified, due to the peritoneal metastasis in both surgical groups.

Perri et al. (43) and George et al. (31) found a 3-fold increased risk for metastasis if the tumour was morcellated [hazard ratio (HR): 2.85; 95\% CI: (1.05-7.5); HR: 2.95; 95\% CI: (1.5-6.0)] $(31,43)$, and a significantly shorter DFS $(p=0.03$ and $p=0.002$, respectively), which was similar to the results from Park et al. (45) who showed a significantly reduced OS and DFS in 56 patients with stage I and II LMS. Here, patients with a morcellation had more peritoneal and vaginal cuff metastasis.

Table 3. Surgical management, adjuvant therapy and outcome of patients with uterine sarcoma

\begin{tabular}{|c|c|c|c|c|c|c|c|}
\hline \multicolumn{2}{|l|}{ Variable } & $\begin{array}{l}\text { All sarcomas } \\
n=57\end{array}$ & $\begin{array}{l}\text { LMS } \\
n=25\end{array}$ & $\begin{array}{l}C S \\
n=19\end{array}$ & $\begin{array}{l}\text { ESS } \\
\mathbf{n}=9\end{array}$ & $\begin{array}{l}\mathbf{A S} \\
\mathbf{n}=\mathbf{3}\end{array}$ & $\begin{array}{l}\text { Other } \\
n=1\end{array}$ \\
\hline \multirow{4}{*}{ Hysterectomy n (\%) } & Abdominal & $51(89.5 \%)$ & $21(84.0 \%)$ & $19(100.0 \%)$ & $8(88.9 \%)$ & $2(66.7 \%)$ & $1(100.0 \%)$ \\
\hline & Laparoscopic & $3(5.3 \%)$ & $2(8.0 \%)$ & $0(0 \%)$ & $0(0 \%)$ & $1(33.3 \%)$ & $0(0 \%)$ \\
\hline & Vaginal & $1(1.8 \%)$ & $1(4.0 \%)$ & $0(0 \%)$ & $0(0 \%)$ & $0(0 \%)$ & $0(0 \%)$ \\
\hline & Aborted surgery & $2(3.5 \%)$ & $1(4.0 \%)$ & $0(0 \%)$ & $1(11.1 \%)$ & $0(0 \%)$ & $0(0 \%)$ \\
\hline \multirow{4}{*}{ ASA score, n (\%) } & I & $5(8.8 \%)$ & $4(16.0 \%)$ & $0(0 \%)$ & $1(11.1 \%)$ & $0(0 \%)$ & $0(0 \%)$ \\
\hline & II & $21(36.8 \%)$ & $11(44.0 \%)$ & $4(21.1 \%)$ & $5(55.6 \%)$ & $1(33.3 \%)$ & $0(0 \%)$ \\
\hline & III & $25(43.9 \%)$ & $7(28.0 \%)$ & $13(68.4 \%)$ & $2(22.2 \%)$ & $2(66.7 \%)$ & $1(100.0 \%)$ \\
\hline & Missing & $6(10.5 \%)$ & $3(12.0 \%)$ & $2(10.5 \%)$ & $1(11.1 \%)$ & $0(0 \%)$ & $0(0 \%)$ \\
\hline \multirow{3}{*}{$\begin{array}{l}\text { Radiotherapy } \\
\text { postoperative n (\%) }\end{array}$} & No & $10(17.5 \%)$ & $4(16.0 \%)$ & $3(15.8 \%)$ & $3(33.3 \%)$ & $0(0 \%)$ & $0(0 \%)$ \\
\hline & Yes & $11(19.3 \%)$ & $5(20.0 \%)$ & $6(31.6 \%)$ & $0(0 \%)$ & $0(0 \%)$ & $0(0 \%)$ \\
\hline & Missing & $36(63.2 \%)$ & $16(64.0 \%)$ & $10(52.6 \%)$ & $6(66.7 \%)$ & $3(100.0 \%)$ & $1(100.0 \%)$ \\
\hline \multirow{3}{*}{$\begin{array}{l}\text { Chemo-therapy } \\
\text { postoperative n (\%) }\end{array}$} & No & $11(19.3 \%)$ & $4(16.0 \%)$ & $5(26.3 \%)$ & $2(22.2 \%)$ & $0(0 \%)$ & $0(0 \%)$ \\
\hline & Yes & $25(43.9 \%)$ & $14(56.0 \%)$ & $9(47.4 \%)$ & $0(0 \%)$ & $1(33.3 \%)$ & $1(100.0 \%)$ \\
\hline & Missing & $21(36.8 \%)$ & $7(28.0 \%)$ & $5(26.3 \%)$ & $7(77.8 \%)$ & $2(66.7 \%)$ & $0(0 \%)$ \\
\hline \multirow{3}{*}{ Recurrence, n (\%) } & No & $14(24.6 \%)$ & $3(12.0 \%)$ & $6(31.6 \%)$ & $4(44.4 \%)$ & $1(33.3 \%)$ & $0(0 \%)$ \\
\hline & Yes & $20(35.1 \%)$ & $11(44.0 \%)$ & $7(36.8 \%)$ & $0(0 \%)$ & $1(33.3 \%)$ & $1(100.0 \%)$ \\
\hline & Missing & $23(40.4 \%)$ & $11(44.0 \%)$ & $6(31.6 \%)$ & $5(55.6 \%)$ & $1(33.3 \%)$ & $0(0 \%)$ \\
\hline \multirow{3}{*}{ Death, n (\%) } & No & $31(54.4 \%)$ & $12(48.0 \%)$ & $10(52.6 \%)$ & $5(55.6 \%)$ & $3(100.0 \%)$ & $1(100.0 \%)$ \\
\hline & Yes & $25(43.9 \%)$ & $12(48.0 \%)$ & $9(47.4 \%)$ & $4(44.4 \%)$ & $0(0 \%)$ & $0(0 \%)$ \\
\hline & Missing & $1(1.8 \%)$ & $1(4.0 \%)$ & $0(0 \%)$ & $0(0 \%)$ & $0(0 \%)$ & $0(0 \%)$ \\
\hline
\end{tabular}

Time interval 2002-2015, from a comprehensive database of the cancer centre of Ulm University; LMS: Leiomyosarcoma; ESS: Endometrioid stroma sarcoma; CS: Carcinosarcomas; AS: Adenosarcoma; Other: Sarcoma without further classification/details; ASA: American Society of Anesthesiologists 

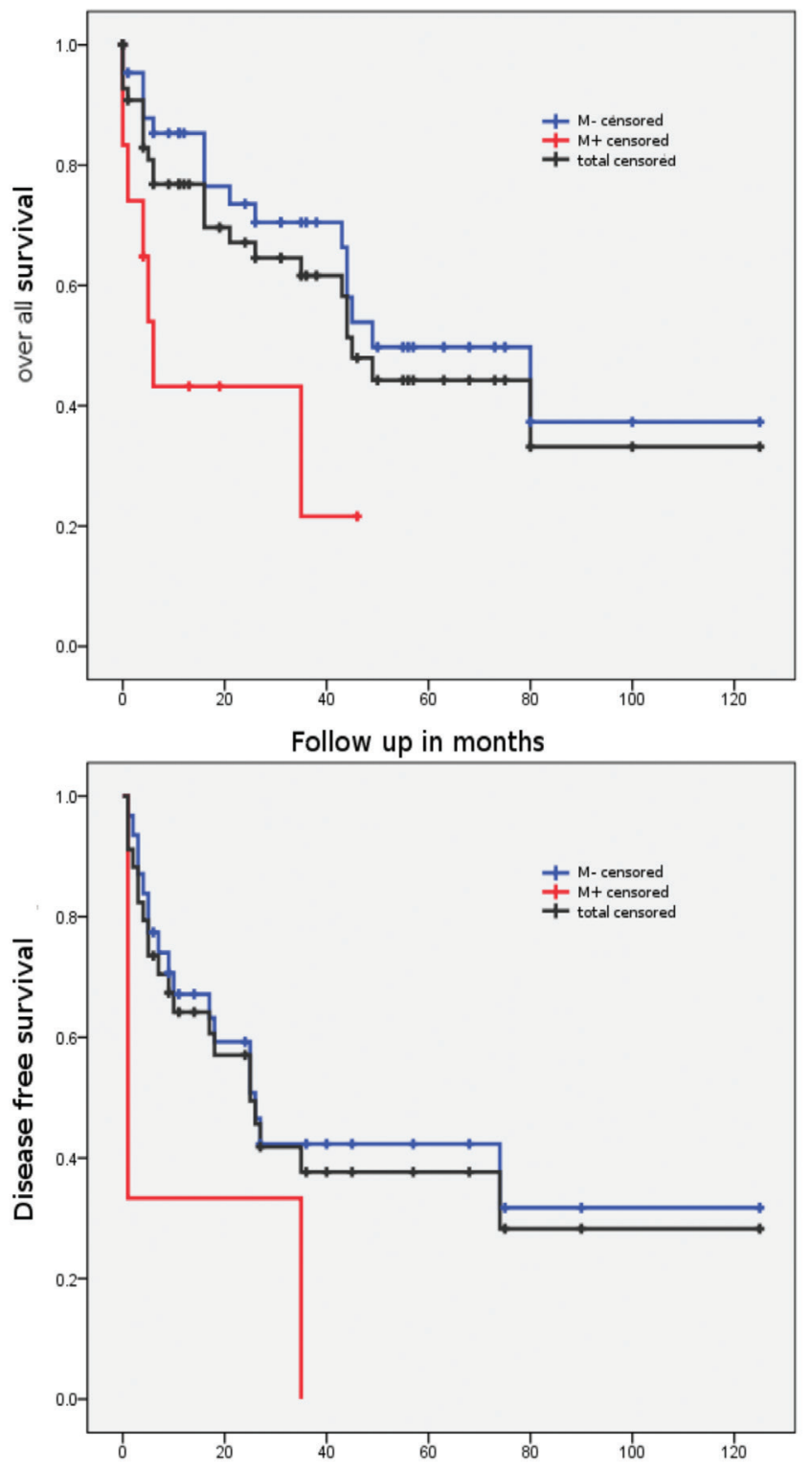

Figure 1. Disease-free survival and overall survival for all patients and the two subgroups. The disease-free survival difference $M+/$ - is not statistically significant but should be considered clinically relevant. Patients with morcellation of the sarcoma (M+), no morcellation (M-)

The most current published data indicate that patients with uterine LMS may have a shorter DFS and OS. Due to the low numbers in our analysis, the DFS difference of 42.6 months was not statistically different, but still should be considered clinically relevant.

In early-stage low-grade endometrial stroma sarcoma, Park et al. (42) found a significantly shorter DFS but a longer, non-significant, 5-year OS for a morcellation subgroup. According to the authors the prolonged survival might be due to the more aggressive systemic therapy in case of morcellation and the short follow up. However, the incidence of accidental morcellation of uterine sarcoma seems to be low. In a large German monocentric retrospective study, the overall rate of uterine malignancies was $0.13 \%$ in more than 10,000 patients with morcellated uteri during laparoscopicassisted supracervical hysterectomy. Thereby, the majority of malignancies were endometrial cancer $(0.07 \%)$ with only $0.06 \%$ sarcomas [4 endometrial stromal sarcomas (0.04\%) and 2 LMS $(0.02 \%)](46)$. As with any rare diseases, our retrospective database misses information on tumour classifications, followup, and most of all, the conclusions drawn from the analysis are restricted by the small number of cases. Unfortunately this also applies to most of the current literature regarding uterine sarcoma (47).

Only a few authors clearly differ between the subtypes of sarcoma $(31,42,43)$. Other studies, like ours, included various subtypes in the analysis. Some tumour variables cannot be provided by the pathologist. For example, the sarcoma size cannot be measured on a morcellated uterus. Thereby, this factor is a limiting point in study analysis and is important for appropriate assessment of tumour stage, and further required adjuvant therapy and can impact the ability to identify pathologic features for the determination of the tumour entity. In summary, a retrospective database will always miss certain information on the tumour that might be vital for further analysis. However, a prospective randomised trial with a known uterine sarcoma and deliberate morcellation on basis of the current data is unethical. Accordingly, the only possible and ethical way to increase knowledge on these rare diseases is through retrospective studies.

Although this is a small, retrospective analysis, it includes all patients with uterine sarcoma over a time period of 13 years at a university hospital and investigates the impact of intraoperative morcellation. OS significantly differed between the intraoperative morcellation $(\mathrm{M}+)$ and whole-tumour resection (M-) subgroups. DFS also showed a clear, clinically relevant trend to impaired survival within the $\mathrm{M}+$ group, but did not show a statistically significant difference. This is a common statistical issue with such small patient and follow-up numbers. Relapse mostly occurred as distant relapse. In contrast to some requests for abandoning morcellation in gynaecologic surgery, we recommend careful preoperative review and informed consent of intraoperative morcellation. This approach is in line with the Society of Gynecologic Oncology and the German Society for Gynecology and Obstetrics because purposeful use of morcellation allows less invasive surgery with reduced patients morbidity (48-50).

Although the overall numbers of patients treated with uterine sarcomas at our certified oncologic university centre is low, the rate of morcellated sarcomas (13 out of 57 ) underlies the 
clinical relevance of the topic. To address the clinical demand for improved identification strategies, we are currently performing a prospective liquid biopsy study on all patients with suspected LMS and storing the drawn blood samples for further investigation in our biobank. Possible target markers include vascular endothelial growth factor and cell-free RNA with evaluation of their use as prognostic and predictive factors. Other studies are also investigating possible mutations in sarcomas for personalized systemic treatment options (51). Our data support resection of the entire uterus if any malignancy including sarcoma is suspected or known. For patients and physicians, a reliable presurgical test to eliminate the risk of uterine sarcoma is urgently needed.

Ethics Committee Approval: Ethics approval (308/2012) was given by the Local Ethic Committee of Ulm University.

Informed Consent: It was taken.

Peer-review: Externally peer-reviewed.

Author Contributions: Concept - S.W., F.E.; Design - S.W., F.E.; Supervision - W.J., N.d.G.; Materials - S.W., F.E.; Data Collection and Processing - F.E.; Analysis and Interpretation - F.E., A.d.G., I.B.; Writer - F.E., A.d.G., I.B.

Conflict of Interest: No conflict of interest is declared by the authors.

Financial Disclosure: The authors declared that this study received no financial support.

\section{References}

1. Hagemann IS, Hagemann AR, LiVolsi VA, Montone KT, Chu CS. Risk of occult malignancy in morcellated hysterectomy: a case series. Int J Gynecol Pathol 2011; 30: 476-83.

2. Leung F, Terzibachian JJ, Gay C, Chung Fat B, Aouar Z, Lassabe C, et al. [Hysterectomies performed for presumed leiomyomas: should the fear of leiomyosarcoma make us apprehend non laparotomic surgical routes?]. Gynécol Obstet Fertil 2009; 37: 109-14.

3. Gregorio N, Ebner F, Scholz C, Wöckel A, Janni W, Varga D. Erkennen des Uterussarkoms. Gynacologe 2014; 47: 31-4.

4. Scholz C, Wöckel A, Ebner F, Reich A, Janni W. Uteruserhaltende Myomchirurgie - Springer Medizin. Gynacologe 2012: 841-6.

5. Tropé CG, Abeler VM, Kristensen GB. Trope Diagnosis and treatment of sarcoma of the uterus a review [Internet]. Acta oncologica (Stockholm, Sweden). 2012 [cited 2012 Nov 15]. p. 694705. Available from: http://informahealthcare.com/doi/pdf/10.3109/ 0284186X.2012.689111

6. Hendrickson M, Tavassoli F, Kempson R, McCluggage WG, Haller U, Kubik-Huch RA. Mesenchymal tumors of the uterus and related lesions. In: Tavassoli F, Devilee P, editors. Pathology and genetics of tumours of the breast and female genital organs World Health Organization Classification of Tumours. Lyon: IARC Press; 2003. p. 233-49.
7. Kosary, Carol L. Chapter 15: Cancer of the Corpus Uteri. In: Ries LAG, Young JL, Keel GE, Eisner MP, Lin YD HM-J, editors. SEER Survival Monograph: Cancer Survival Among Adults: US SEER Program, 1988-2001, Patient and Tumor Characteristics. NIH Pub. N. Bethesda: National Cancer Institute, SEER Program; 2007. p. 123-32.

8. Thomakos N, Rodolakis A, Zagouri F, Zacharakis D, Sotiropoulou M, Akrivos N, et al. Serum CA 125, CA 15-3, CEA, and CA 19-9: a prognostic factor for uterine carcinosarcomas? Arch Gynecol Obstet 2013; 287: 97-102.

9. Amant F, Coosemans A, Debiec-Rychter M, Timmerman D, Vergote I. Clinical management of uterine sarcomas. Lancet Oncol 2009; 10: 1188-98.

10. Rha SE, Byun JY, Jung SE, Lee SL, Cho SM, Hwang SS, et al. CT and MRI of uterine sarcomas and their mimickers. AJR Am J Roentgenol 2003; 181: 1369-74.

11. Goto A, Takeuchi S, Sugimura K, Maruo T. Usefulness of Gd-DTPA contrast-enhanced dynamic MRI and serum determination of LDH and its isozymes in the differential diagnosis of leiomyosarcoma from degenerated leiomyoma of the uterus. Int J Gynecol Cancer 2002; 12: 354-61.

12. Thomassin-Naggara I, Dechoux S, Bonneau C, Morel A, Rouzier $\mathrm{R}$, Carette MF, et al. How to differentiate benign from malignant myometrial tumours using MR imaging. Eur Radiol 2013; 23: 2306-14.

13. Gadducci A, Cosio S, Romanini A, Genazzani AR. The management of patients with uterine sarcoma: a debated clinical challenge. Crit Rev Oncol Hematol 2008; 65: 129-42.

14. Nitta E, Kanenishi K, Itabashi N, Tanaka H, Hata T. Real-time tissue elastography of uterine sarcoma. Arch Gynecol Obstet 2014; 289: 463-5.

15. Lundholm C, Forsgren C, Johansson AL, Cnattingius S, Altman D. Hysterectomy on benign indications in Sweden 1987-2003: a nationwide trend analysis. Acta Obstet Gynecol Scand 2009; 88: 52-8.

16. Pitter MC, Simmonds C, Seshadri-Kreaden U, Hubert HB. The impact of different surgical modalities for hysterectomy on satisfaction and patient reported outcomes. Interact J Med Res 2014; 3: 11.

17. Wright JD, Ananth CV, Lewin SN, Burke WM, Lu YS, Neugut AI, et al. Robotically assisted vs laparoscopic hysterectomy among women with benign gynecologic disease. JAMA 2013; 309: 689-98.

18. O'Hanlan KA, McCutcheon SP, McCutcheon JG. Laparoscopic Hysterectomy: Impact of Uterine Size. J Minim Invasive Gynecol 2011; 18: 85-91.

19. Sinha R, Sundaram M, Lakhotia S, Mahajan C, Manaktala G, Shah P. Total laparoscopic hysterectomy for large uterus. J Gynecol Endosc Surg 2009; 1: 34-9.

20. Bardens D, Solomayer E, Baum S, Radosa J, Gräber S, Rody A, et al. The impact of the body mass index (BMI) on laparoscopic hysterectomy for benign disease. Arch Gynecol Obstet 2014; 289: 803-7.

21. Malzoni M, Perniola G, Hannuna K, Iuele T, Fruscella ML, Basili R, et al. [A review of 445 cases of laparoscopic hysterectomy: benefits and outcome]. Clin Ter 2004; 155: 9-12.

22. Elessawy M, Schollmeyer T, Mettler L, Jonat W, Schem C, von Hehn $\mathrm{U}$, et al. The incidence of complications by hysterectomy for benign disease in correlation to an assumed preoperative score. Arch Gynecol Obstet 2015; 292: 127-33.

23. Stine JE, Clarke-Pearson DL, Gehrig PA. Uterine morcellation at the time of hysterectomy: techniques, risks, and recommendations. Obstet Gynecol Surv 2014; 69: 415-25.

24. Durnali A, Tokluoğlu S, Özdemir N, Inanç M, Alkiş N, Zengin N, et al. Prognostic factors and treatment outcomes in 93 patients with uterine sarcoma from 4 centers in Turkey. Asian Pac J Cancer Prev 2012; 13: 1935-41.

25. Tropé CG, Abeler VM, Kristensen GB. Diagnosis and treatment of sarcoma of the uterus. A review. Acta Oncol 2012; 51: 694-705. 
26. Park JY, Park SK, Kim DY, Kim JH, Kim YM, Kim YT, et al. The impact of tumor morcellation during surgery on the prognosis of patients with apparently early uterine leiomyosarcoma. Gynecol Oncol 2011; 122: 255-9.

27. Naaman Y, Shveiky D, Ben-Shachar I, Shushan A, Mejia-Gomez J, Benshushan A. Uterine sarcoma: prognostic factors and treatment evaluation. Isr Med Assoc J 2011; 13: 76-9.

28. El Husseiny G, Al Bareedy N, Mourad WA, Mohamed G, Shoukri M, Subhi J, et al. Prognostic factors and treatment modalities in uterine sarcoma. Am J Clin Oncol 2002; 25: 256-60.

29. Gadducci A, Cosio S, Romanini A, Genazzani AR. The management of patients with uterine sarcoma: A debated clinical challenge. Crit Rev Oncol Hematol 2008; 65: 129-42.

30. Ghaemmaghami F, Karimi-Zarchi M, Gilani MM, Mousavi A, Behtash N, Ghasemi M. Uterine Sarcoma: Clinicopathological Characteristics, Treatment and Outcome in Iran. Asian Pac J Cancer Prev 2008; 9: 421-6.

31. George S, Barysauskas C, Serrano C, Oduyebo T, Rauh-Hain JA, Del Carmen MG, et al. Retrospective cohort study evaluating the impact of intraperitoneal morcellation on outcomes of localized uterine leiomyosarcoma. Cancer 2014; 120: 3154-8.

32. Coquard R, Romestaing P, Ardiet JM, Mornex F, Sentenac I, Gérard JP. [Uterine sarcoma treated by surgery and postoperative radiation therapy. Patterns of relapse, prognostic factors and role of radiation therapy]. Bull Cancer 1997; 84: 625-9.

33. Koivisto-Korander R, Butzow R, Koivisto AM, Leminen A. Clinical outcome and prognostic factors in 100 cases of uterine sarcoma: experience in Helsinki University Central Hospital 1990-2001. Gynecol Oncol 2008; 111: 74-81.

34. Tirumani SH, Ojili V, Shanbhogue AK, Fasih N, Ryan JG, Reinhold C. Current concepts in the imaging of uterine sarcoma. Abdom Imaging 2013; 38: 397-411.

35. Cucinella G, Granese R, Calagna G, Somigliana E, Perino A. Parasitic myomas after laparoscopic surgery: an emerging complication in the use of morcellator? Description of four cases. Fertil Steril 2011; 96: 90-6.

36. Anupama R, Ahmad SZ, Kuriakose S, Vijaykumar DK, Pavithran K, Seethalekshmy NV. Disseminated peritoneal leiomyosarcomas after laparoscopic "myomectomy" and morcellation. J Minim Invasive Gynecol 2011; 18: 386-9.

37. Della Badia C, Karini H. Endometrial stromal sarcoma diagnosed after uterine morcellation in laparoscopic supracervical hysterectomy. J Minim Invasive Gynecol 2010; 17: 791-3.

38. Morice P, Rodriguez A, Rey A, Pautier P, Atallah D, Genestie C, et al. Prognostic value of initial surgical procedure for patients with uterine sarcoma: analysis of 123 patients. Eur J Gynaecol Oncol 2003; 24: 237-40.
39. Rekha W, Amita M, Sudeep G, Hemant T. Unexpected complication of uterine myoma morcellation. Aust N Z J Obstet Gynaecol 2005; 45: 248-9.

40. Ebner F, Friedl TW, Scholz C, Schochter F, Janni W, Vorwerk E, et al. Is open surgery the solution to avoid morcellation of uterine sarcomas? A systematic literature review on the effect of tumor morcellation and surgical techniques. Arch Gynecol Obstet 2015; 292: 499-506.

41. Seidman MA, Oduyebo T, Muto MG, Crum CP, Nucci MR, Quade BJ. Peritoneal dissemination complicating morcellation of uterine mesenchymal neoplasms. PLoS One 2012; 7: e50058.

42. Park JY, Kim DY, Kim JH, Kim YM, Kim YT, Nam JH. The impact of tumor morcellation during surgery on the outcomes of patients with apparently early low-grade endometrial stromal sarcoma of the uterus. Ann Surg Oncol 2011; 18: 3453-61.

43. Perri T, Korach J, Sadetzki S, Oberman B, Fridman E, Ben-Baruch G. Uterine leiomyosarcoma: does the primary surgical procedure matter? Int J Gynecol Cancer 2009; 19: 257-60.

44. Liu FW, Galvan-Turner VB, Pfaendler KS, Longoria TC, Bristow RE. A critical assessment of morcellation and its impact on gynecologic surgery and the limitations of the existing literature. Am J Obstet Gynecol 2015; 212: 717-24.

45. Park JY, Park SK, Kim DY, Kim JH, Kim YM, Kim YT, et al. The impact of tumor morcellation during surgery on the prognosis of patients with apparently early uterine leiomyosarcoma. Gynecol Oncol 2011; 122: 255-9.

46. Bojahr B, De Wilde RL, Tchartchian G. Malignancy rate of 10,731 uteri morcellated during laparoscopic supracervical hysterectomy (LASH). Arch Gynecol Obstet 2015; 292: 665-72.

47. Bogani G, Cliby WA, Aletti GD. Impact of morcellation on survival outcomes of patients with unexpected uterine leiomyosarcoma: a systematic review and meta-analysis. Gynecol Oncol 2015; 137: 167-72.

48. Statement of the Society of Gynecologic Oncology to the Food and Drug Administration's Obstetrics and Gynecology Medical Devices Advisory Committee Concerning Safety of Laparoscopic Power Morcellation July 10-11, 2014 https://www.sgo.org/wp-content/ uploads/2014/04/SGO-Testimony-to-FDA-on-Power-MorcellationFINAL.pdf accessed 29.8.2018.

49. Beckmann MW, Juhasz-Böss I, Denschlag D, Gaß P, Dimpfl T, Harter P, et al. Surgical Methods fort he Treatment of Uterine Fibroids - Risk of Uterine Sarcoma and Problems of Morcellation: Position Paper of the DGGG. Geburtshilfe Frauenheilkd 2015; 75: 148-64.

50. Chalas E. Morcellation in gynecologic oncology. Curr Opin Obstet Gynecol 2018; 30: 96-8.

51. Chudasama P, Mughal SS, Sanders MA, Hübschmann D, Chung I, Deeg KI, et al. Integrative genomic and transcriptomic analysis of leiomyosarcoma. Nat Commun 2018; 9: 144. 